\title{
ACTIVE CONTROL OF AEROTHERMOELASTIC EFFECTS FOR A CONCEPTUAL HYPERSONIC AIRCRAFT
}

Jennifer Heeg, Michael G. Gilbert, and Anthony S. Pototzky

August 1990

(NASA-TM-10?713) ACTIV CHTOUL OF
AERTTHERMTELASTIC EFFTCTS FOR A CONCEPTUAL

AERTTHERMTELASTIC LFF COSASA) $12 \%$ CSCL OIC

$63 / 09 \quad 0303191$

$100-277 ?$

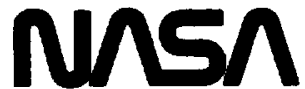

National Aeronautics and

Space Administration

Langley Research Center

Hampton, Virginia 23665-5225 



\title{
ACTIVE CONTROL OF AEROTHERMOELASTIC EFFECTS FOR A CONCEPTUAL HYPERSONIC AIRCRAFT
}

\author{
Jennifer Heeg* and Michael G. Gilbert** \\ NASA Langley Research Center \\ and \\ Anthony S. Pototzky* \\ Lockheed Engineering and Sciences Company
}

\begin{abstract}
This paper describes the procedures for and results of aeroservothermoelastic studies. The objectives of these studies were to develop the necessary procedures for performing an aeroelastic analysis of an aerodynamically heated vehicle and to analyze a configuration in the classical "cold" state and in a "hot" state. Major tasks include the development of the structural and aerodynamic models, open loop analyses, design of active control laws for improving dynamic responses and analyses of the closed loop vehicles. The analyses performed focused on flutter speed calculations, short period eigenvalue trends and statistical analyses of the vehicle response to controls and turbulence. Improving the ride quality of the vehicle and raising the flutter boundary of the aerodynamically-heated vehicle up to that of the cold vehicle were the objectives of the control law design investigations.
\end{abstract}

\section{Vomenclature}

\begin{tabular}{|c|c|c|}
\hline a & $=$ & speed of sound \\
\hline$A_{0}, A_{1}$ & $=$ & $\begin{array}{l}\text { coefficients of the aerodynamic } \\
\text { approximation }\end{array}$ \\
\hline b & $=$ & wing root semi-chord \\
\hline c & $=$ & wing root chord \\
\hline$\underline{M}$ & $=$ & Mach number \\
\hline $\bar{q}$ & $=$ & dynamic pressure \\
\hline $\mathbf{s}$ & $=$ & Laplace variable \\
\hline V & $=$ & velocity \\
\hline$(x, y, z)$ & $=$ & $\begin{array}{l}\text { Cartesian coordinates describing the } \\
\text { location of the box centers used in the } \\
\text { Piston Theory aerodynamic calculations }\end{array}$ \\
\hline $\mathrm{Z}$ & $=$ & $\begin{array}{l}\text { distance from the mean camber line to } \\
\text { the airfoil skin }\end{array}$ \\
\hline$\Delta \mathrm{p}$ & $=$ & $\begin{array}{l}\text { pressure difference across an } \\
\text { aerodynamic surface }\end{array}$ \\
\hline$\xi$ & $=$ & generalized coordinate \\
\hline$\gamma$ & $=$ & ratio of specific heats \\
\hline$\rho$ & $=$ & density \\
\hline$\omega$ & $=$ & circular frequency \\
\hline
\end{tabular}

* Member, AIAA

** Senior Member, AIAA

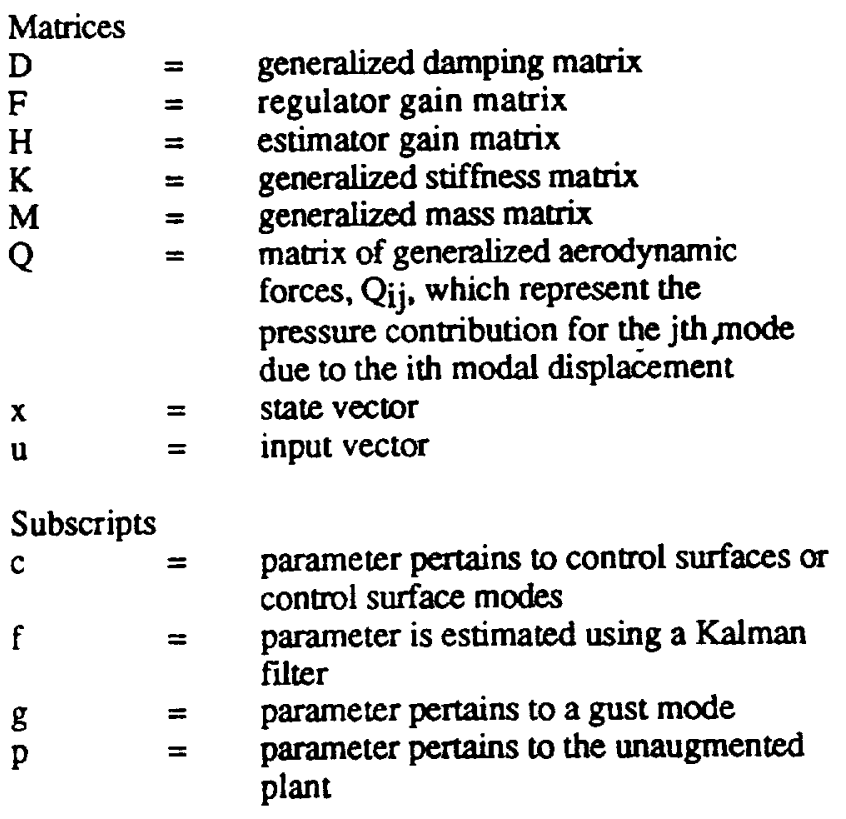

\section{Introduction}

The proposed flight envelope of the National AeroSpace Plane (NASP) includes Mach numbers from low subsonic to hypersonic speeds. As a result, the flight vehicle will experience a wide range of dynamic pressures and aerodynamic heat loads which may degrade the aeroelastic response characteristics of the vehicle. The single-stage-to-orbit mission of the NASP requires a large vehicle with a high fuel mass fraction. These conditions generally result in flexible configurations having low structural frequencies. Thus, both the flight environment and the required vehicle characteristics may cause structural designs to exhibit aeroelastic instabilities.

The work described in this paper is part of a research effort at the NASA Langley Research Center to develop analytical methods for predicting the aeroelastic characteristics of hypersonic aircraft with active control systems. Major tasks associated with this activity include: 1) construction of a generic hypersonic model for use in performing these analytical studies, 2) development and analysis of aeroelastic models which incorporate the effects of aerodynamic heating, and 3) application of active controls to improve aeroelastic response. Flutter suppression and ride quality augmentation systems were 
designed and evaluated for the aircraft in its classical cold state and for the aerodynamically heated state.

\section{Modeling and Equations of Motion}

\section{Aeroservothermoelastic Modeling}

Aeroservothermoelastic modeling, by definition, incorporates aerodynamics, controls, temperaturedependent material properties and the structural definition of the configuration. The flow chart in Figure 1 presents the analysis and control system design approach taken. The three major aspects of the model development are described in the boxes on the left. These include determination of thermal loads, construction of a finite element model and calculation of unsteady aerodynamic forces. These data are combined to form aeroelastic equations of motion for the aerodynamically-heated vehicle. Open loop analyses are performed on these models which also serve as a testbed for control law design. After control laws have been formulated, closed loop analyses and simulation may be conducted.

A more detailed accounting of the procedure for the model development task [1] is given in Figure 2. The individual processes are indicated by bracketed numbers. The initial step is to perform a trim analysis (1) of the vehicle in a rigid and unheated state to find the approximate flight attitude and control surface settings. A steady aerodynamic analysis (2) is then performed to determine the external pressures, the aerodynamic heating rates and the radiation equilibrium wall temperatures. These radiation equilibrium wall temperatures are used to approximate the temperature loading on the elastic finite element model. A thermal structural analysis (3) is performed to determine the temperatures at each of the node locations. New vehicle shape and stiffnesses are determined by performing a static structural elastic analysis $(4 \& 5)$. The nodal temperature data and the temperature-dependent material properties are incorporated with the geometric and element definitions to yield the finite element data sets which contain structural properties for each element based on the local temperature. The temperature-induced intemal stresses on the vehicle are also computed using the nodal temperature data as a thermal load case. These stresses are incorporated into the stiffness matrix, which has already been changed to reflect the material properties changes associated with heating the vehicle. A classical vibration analysis (6) is then performed using the effective stiffness matrix. The resultant mode shapes and natural frequencies are input into an unsteady aerodynamic analysis $(7 \& 8)$ to determine generalized aerodynamic forces,(GAF's), required for stability analyses, control law design tasks, etc.

\section{Geometric and Finite Element Model Descriptions}

Isotropic Titanium-Aluminide was used as the material model for the generic configuration. The temperature dependence of material properties, (the
Young's modulus, the shear modulus and the thermal expansion coefficient), are included in the modeling. The geometric and inertial properties of the configuration are detailed in Figure 3 and Table 1. The finite element model, shown in Figure 4, consists of five components: the fuselage, wingbox, aileron, flap and wing tip-mounted fin. The fuselage has an elliptical cross-section with the width being twice the height. Ring and skin construction, using very stiff rings, prevents shell or "breathing" modes of the fuselage. The low-aspect ratio wing is constructed with spars, ribs and skins, and is fully attached to the fuselage. The wing has a 70-degree leading edge sweep and a 3-percent circular arc airfoil. The control surfaces consist of an all-movable vertical fin, flaps, and ailerons.

\section{Vibration Mode Shapes}

Two sets of structural vibration data (mode shapes and frequencies) were generated: one which contained the aerodynamic heating effects and one which did not. All heating effects were based on the Mach 4 flight condition. Both structural models, cold and hot, were analyzed at Mach 2 and Mach 4 . Thus, the hot Mach 2 flight condition was assumed to be representative of the deceleration phase of the mission profile. The Mach 4 cold model was assumed to be in an acceleration phase such that the vehicle has not yet been affected by the aerodynamic heating. Since there were no visible differences between the "hot" mode shapes and the "cold" mode shapes, only one set of vibration mode shapes is shown in Figure 5. Note that the first and third elastic modes include significant fuselage motion. The frequencies, hot and cold, for each of the first six modes are listed in Table 2 . As previously mentioned, the mission requirements cause the frequencies for this class of vehicle to be very low. Without aerothermal effects, the frequencies lie between 3 and 11 Hertz. When the effects of heating were incorporated, the frequencies drop by 13 to 20 percent, indicating the destiffening effect of the aerodynamic heat loads.

\section{Aerodynamics}

Supersonic generalized aerodynamic forces were generated using van Dyke's second order Piston Theory [2], including the effects of airfoil thickness and non-rigid chords. The validity of the calculated GAFs was substantiated by computing stability derivatives and short period behavior and comparing the calculations with steady-state results [3].

Piston Theory - The premise behind Piston Theory aerodynamics is that the relationship between the local pressure and the normal free-stream velocity at a point is analogous to the relationship between the pressure in a one-dimensional piston chamber and the velocity of the piston. At sufficiently high Mach numbers this analogy is valid, and local wave theory gives a good approximation of the unsteady aerodynamics. 
The local, linearized pressure equation used in this Piston Theory Method is given as:

$\Delta p(x, y, t)=-2 \rho a\left[1+G \frac{\partial}{\partial x} z(x, y)\right]\left(v \frac{\partial}{\partial x}+\frac{\partial}{\partial t}\right) z(x, y, t)$

where

$$
G=\frac{M^{4}(\gamma+1)-4 \beta^{2}}{2 \beta^{2}}
$$

and

$$
\beta=\sqrt{M^{2}-1}
$$

The variable " $z$ " represents both the spatial dependence and the time-varying displacement of a point. This displacement is calculated at discrete points on the surface of the vehicle by representing the wing surface and projection of the fuselage onto the $x-y$ plane with trapezoidal boxes. Using surface spline interpolation the displacement of the center of the boxes was computed from the mode shapes. Normal velocities over the wing and fuselage projection surfaces were computed by assuming simple harmonic motion of each mode. The upper case " $\mathrm{Z}$ " is the distance from the mean camber line to points on the skin, thus representing the thickness. The circular arc airfoil thickness characteristics of the wing were incorporated into the pressure equation, however, the thickness effect of the fuselage was not included in the aerodynamic modeling. " The point forces resulting from the Piston Theory pressures were also concentrated at the center of each box. The generalized aerodynamic force for each mode was generated by summing these point forces, weighted by the interpolated mode shapes, over the wing and fuselage surfaces.

\section{Equations of Motion}

Classical open loop aeroelastic equations of motion were formulated for the longitudinal degrees of freedom. These equations of motion, based on two rigid body and the first six vehicle vibration modes are derived using Lagrangian energy equations. They represent the summation of inertial, dissipative and internal restorative forces along with the reduced-frequency dependent aerodynamic forces which are induced by the rigid body and structural motion, control deflections and gusts. Small perturbation equations, referenced to level equilibrium flight, were constructed to represent a linearized system of equations expressed in terms of generalized coordinates. As described in Reference 4,

* At the time that the analysis and control law design were performed, the Piston Theory computer code did not have the capability of including the thickness effects of the fuselage. The assumption that the contribution to the GAF's would cause only small changes in the dynamics was made and subsequently validated. After enhancing the Piston Theory code to incorporate the fuselage thickness effects, the flutter dynamic pressure increased by two percent. when transformed into the Laplace domain the equations of motion can be written:

$$
\left([\mathrm{M}] \mathrm{s}^{2}+[\mathrm{D}] \mathrm{s}+[\mathrm{K}]\right) \xi+\overline{\mathrm{q}}[\mathrm{Q}]\left\{\begin{array}{c}
\xi \\
\xi_{\mathrm{c}}
\end{array}\right\}=\left[\mathrm{Q}_{\mathrm{g}}\right] \frac{\xi_{\mathrm{g}}}{\mathrm{V}}
$$

where $\xi$ are generalized displacements of the rigid and flexible modes.

\section{Aerodynamic Approximations}

Generalized Aerodynamic Forces (GAF's) predicted using classical unsteady aerodynamics codes result in matrix sets of data at discrete values of reduced frequency. In order to incorporate the data into the Laplace domain aeroelastic equations, they must be transformed into continuous functions of the Laplace variable s. To this end, an approximation is generally made, employing a curve fit to the tabular data [5]. By examining a typical variation in GAF with reduced frequency, as seen in Figure 6, it is observed that, in the case of Piston Theory aerodynamics, the real parts of the GAF's are constant and the imaginary parts are linear with reduced frequency. This characteristic allows the Piston Theory aerodynamics to be represented exactly by a first order equation:

$$
Q_{i j}=A_{0}+A_{1} \frac{b}{V} s
$$

where $A_{0}$ is the constant value of the real part and $A_{1}$ is the slope of the imaginary part.

\section{State Space Equations}

Control system design and analysis are more readily performed using a state space representation of the equations of motion. The transformation of the equations into first order form results in

$$
\dot{\mathrm{x}}=\mathrm{Ax}+\mathrm{Bu},
$$

where

$$
\begin{aligned}
& x=\left\{\begin{array}{l}
x_{p} \\
\dot{x}_{p}
\end{array}\right\} \quad u=\left\{\begin{array}{l}
\xi_{c} \\
\dot{\xi}_{c} \\
\xi_{g} \\
\dot{\xi}_{g}
\end{array}\right\} \\
& A=\left[\begin{array}{cc}
0 & I \\
-M^{-1} \bar{K} & -M^{-1} \bar{D}
\end{array}\right] \\
& B=\left[\begin{array}{cccc}
0 & 0 & 0 & 0 \\
-M^{-1} A_{0 c} & -M^{-1} A_{1 c} & M^{-1} A_{0 g} & M^{-1} A_{1 g}
\end{array}\right] \\
& \overline{\mathrm{D}}=\mathrm{D}+\frac{\overline{\mathrm{q}} \mathrm{c}}{2 \mathrm{~V}} \mathrm{~A}_{1}, \overline{\mathrm{K}}=\mathrm{K}+\overline{\mathrm{q}} \mathrm{A}_{0}
\end{aligned}
$$


as described in detail in Reference 4. Note that the aerodynamics, when expressed by the $A_{0}$ and $A_{1}$ coefficients, appear in the linear time-invariant equations as damping and stiffness increments. The above equations describe the flexible airplane dynamics. They were augmented with equations representing two thirdorder actuators, which brought the total number of states to 22. The output equations consist of angle of attack, pitch rate of the center of gravity and the pilot station, and the normal acceleration at six fuselage and wing locations.

\section{Open Loop Analyses}

To identify the open loop plant characteristics, trends in the rigid body and aeroelastic characteristics with Mach number, aerodynamic heating and structural flexibility were calculated [6].

\section{Short Period Dynamics}

The short period mode dynamics are influenced by both the aircraft flexibility and by the aerodynamics. Figure 7 provides a root locus plot which shows the changes in short period behavior incurred due to the effects of structural flexibility, aerodynamic heating and Mach number. The six curves represent the trace of the short period eigenvalue in the complex plane as the altitude is varied (altitude decreases from right to left along each curve).

In an aeroelastic system, the roots of any one mode are influenced by the other modes near it. Because the structural frequencies for these configurations are low, in the neighborhood of the rigid body frequency, it is anticipated that they would exhibit a large degree of influence over the short period mode. This influence can be seen by examining the roots of the rigid vehicle versus the eigenvalues after the effects of flexibility have been included. The figure indicates that including flexibility tends to have a destabilizing effect, since the roots move closer to the imaginary axis, which is the neutral stability boundary. The effects due to the aerodynamic heating can be evaluated by comparing the hot and cold data for the same Mach number. At either Mach number, the destabilizing effect of the heating is seen as the roots for the hot data fall further to the right in the s-plane than those corresponding to the cold data.

To determine the effects of the Mach number, the curves for the rigid data, the hot data and the cold data must be examined separately. It is seen that as the Mach number is increased, the short period frequency is increased and the damping is decreased. Thus, increasing Mach number also has a destabilizing effect on the short period dynamics.

Comparing the curves in these three ways shows clearly that the Mach number has a much larger influence than either the flexibility or the heating for the condition analyzed.
Flutter

The altitude root locus plot of Figure 8 shows some of the open loop flutter characteristics. These results are for the heated model at Mach 2 . The eigenvalues associated with the vibrational modes are plotted as altitude is lowered. Since this is a matched point analysis, both the density and the velocity are changed. The predicted flutter mechanism involves the coalescence of the third and fourth elastic modes at a dynamic pressure of 4800 psf and at a frequency of 6.7 Hertz. Figure 9 shows the predicted hot and cold flutter boundaries for this vehicle with respect to Mach number. The dynamic pressure was normalized by a reference dynamic pressure, the flutter dynamic pressure at Mach 4 without heating. The region below either curve represents the area of flutter-free flight for that configuration. As the Mach number is increased, the models require higher dynamic pressures be applied before they become unstable. Heating the model lowers the flutter boundary over the entire range of Mach numbers examined in this analysis at Mach 4, the drop in flutter dynamic pressure due to aerodynamic heating was approximately 25 percent.

\section{Frequency Response}

The state space equations of motion were augmented with a second order Dryden gust model and a first order roll-off filter to analyze the gust responses of the system. Open loop transfer functions between the gust input and the normal accelerations on the fuselage indicated dominance of the first and third flexible modes for these outputs. These two modes were previously shown to exhibit substantial fuselage motion. The wing bending and wing torsion modes were nearly unobservable from the pilot station acceleration due to gust input as shown in the power spectral density plot of Figure 10. This figure also illustrates the shift in frequencies due to aerodynamic heating. Although not shown, open loop transfer functions between the control surfaces and the pilot station acceleration were also examined as indicators of controllability.

\section{Active Control Laws}

One of the objectives of this project was to assess the application of active controls technology to counter dynamic responses aggravated by various flight characteristics. As seen in the open loop analyses, aerodynamic heating lowers the flutter boundary substantially. Thus, the first control concept investigated was flutter suppression. The intent was to recover the flutter dynamic pressure lost due to heating; that is, to raise the flutter boundary back up to its original, unheated boundary. The second active control concept investigated was a ride quality augmentation system (RQAS). The length of the vehicle, the aft center-of-gravity location and the low structural stiffness imply that small perturbations will induce large oscillations at the cockpit. The RQAS was designed to reduce the accelerations at the pilot 
station. Figure 11 shows the basic feedback scheme used for each of these independently-designed and evaluated control laws.

\section{Flutter Suppression System}

The objective of this task was to recover the flutter dynamic pressure reductions caused by aerodynamic heating through the use of active controls. The intent was also to determine the sensitivity of the flutter suppression system (FSS) design to changes in flight conditions.

Design Procedure. - A full-order state estimator (Kalman Filter) was used for compensation in the feedback loop. The controller was designed using standard Linear Quadratic Gaussian (LQG) control law design methods with Loop Transfer Recovery (LTR) [7] to improve stability robustness in the face of changes in flight dynamic pressure. Normal acceleration at the pilot station and at a location very near the wing aileron were used as measurements for feedback to the compensator. Both measurements were assumed to be noisy. The FSS control law was designed to minimize the total system energy by weighting the sum of the structural strain and kinetic energies and the commanded control surface deflections (a measure of control energy). The flight condition for the design was Mach 2 just below the flutter dynamic pressure using the hot vehicle dynamics.

The FSS control law is described by the equations

$$
\begin{gathered}
u=F x_{f} \\
\dot{x}_{f}=A x_{f}+B u+H\left(y-C x_{f}\right)
\end{gathered}
$$

where the gain matrices $F$ and $H$ come from the solutions of the linear regulator and Kalman Filter problems. The dynamics for the estimated states $\mathrm{xf}_{\mathrm{f}}$ are appended to the state-space dynamics of the open loop aeroservothermoelastic aircraft model for closed loop performance analysis.

Besults. - The performance of the FSS control law in recovering the cold vehicle flutter dynamic pressure was evaluated by determination of the eigenvalues of the closed loop hot vehicle equations of motion at increasing dynamic pressures. The dynamic pressure was increased by reduction in flight altitude using the match point density for both Mach 2 and 4. The dynamic pressure was increased until an unstable eigenvalue (indicating flutter) was obtained or until the altitude reached sea level. The results are shown in Figure 12 as the ratio of hot to cold flutter dynamic pressure from Mach 2 to 4 for both the open and closed loop cases. The open loop data, previously shown in Figure 9, is along the lower edge of the box with a ratio less than 1.0, indicating the loss in flutter dynamic pressure due to aerothermal heating. The closed loop results are along the upper edge of the box. with the box representing the increase in flutter dynamic pressure due to the FSS control law. Note that the FSS increased the flutter dynamic pressure of the hot vehicle well beyond that of the cold vehicle, with the Mach 2 result limited by meaningful altitude rather than actual flutter. Note, too, that the results for both Mach 2 and 4 are for the same control law indicating the relative robustness of the control law to variations in Mach number. This implies that a FSS system may be implementable on an actual vehicle without extensive gain scheduling.

\section{Bide Quality Augmentation System}

A ride quality augmentation system (RQAS) was designed to assess the potential for reducing the turbulence-induced normal accelerations felt by the pilot due to excessive fuselage flexibility. Additionally, the influence of the aerothermal loads on the closed loop system were to be evaluated.

BQAS Philosophy. - The vehicle vibration mode shapes indicate that the fuselage bending modes occur at low frequencies and influence the aircraft dynamics to a large extent. Open loop analyses have shown that the normal acceleration response to turbulence at the pilot station is dominated by the fuselage modes. The flaps and ailerons are located on the trailing edges of the wings, nearly the entire length of the vehicle away from the point of interest. Without the addition of a canard, fuselage flexibility prohibits the collocation of the feedback sensor and control surface. The accelerometer measurement at the pilot station is used directly as the feedback signal, despite complications due to noncollocation.

Design Model. - The ride quality augmentation system was designed at Mach 4 at 30000 feet, corresponding to a flight velocity of 3980 feet per second. Based on statistical responses and transfer function data, the heated model was more affected by turbulence than the cold model; the indication being that more control power is required to compensate the performance of the hot vehicle. Thus, the RQAS was developed based on the heated configuration and tested for robustness in the face of the aerodynamic heat loads by applying the compensator to the unheated configuration.

Control Law Design. - The RQAS control law was constructed using the same sensor and noise intensities applied for the FSS; the controller was designed via an eigenvalue assignment technique [8]. The transfer function of primary interest in the RQAS design was the normal acceleration response at the pilot station due to gust disturbances. The flap was used as the feedback control surface, after controllability tests indicated that it had several times more influence on this response than the aileron. In placing the eigenvalues, much consideration was given to the fact that the natural frequencies were subject to relatively large variations brought about by the aerodynamic heating. Due to these known "uncertainties," it was desirable to expend very little control effort altering the frequencies. The assigned eigenvalue locations were chosen such that they represent 
shifts along horizontal lines in the complex plane. The modifications were to produce a critically damped short period mode and to increase the damping of the first and second bending modes of the fuselage by a factor of ten.

Results. - The performance of the RQAS control law was evaluated by determining the reduction in the peak accelerations felt at the pilot station and also in the reduction of the root mean square (rms) response. Control with maximum limits were evaluated fo 30 degrees per second. These second specified by for a gust velocity of 41.68 feet per for this flight Federal Air Regulation 25.341a2 [9] Additionally, condition $(30,000$ feet altitude). acceleration at the pilot stacion must not suppress the elsewhere. The rms respons only to severely increase it were tracked as an responses at six vehicle locations criteria. The as an indicator of the violation of this configurations were substantially the heated and unheated was operating as shown in Figure 13 . responses due to a 1-foot-per 13 . The closed loop Ther-second gust are given in demonstrate a 53.8-percent reductior spectral densities for the closed loop heated reduction in peak acceleration reduction for the cold config vehicle and a 77.5-percent

\section{Concluding Remarks}

This paper has described the aeroservothermoelastic modeling, analysis, and control law design performed for a generic hypersonic vehicle subjected to aerodynamic heating. The conclusions are summarized
below. the flutter boundary.

2) Aerodynamic heating flexibility and number each had destabilizing effects on ty and Mach rigid body motion of the vehicle.

3) A flutter suppression system control law more than recovered the cold structure flutter boundary using normal acceleration feedbacks and conventional
control surfaces.

4) The pilot station ride quality in turbulence was improved using full-state feedback gains and the inboard control surface.

\section{References}

[1] Spain, C. V.; Soistmann, D. L.; and Linville, T. W.: "Integration of Thermal Effects Into Finite Results, Aerothermoelastic Analysis With Illustrative Results," NASP CR-1059, August 1989.

[2] Morgan, H. G.; Huckel, V.; and Runyan, H. L. "Procedure for Calculating Flutter at High Supersonic Speed Including Camber Deflections, and Comparison With Experimental Results," NACA TN-4335, September 1958.

[3] Divan, P.: "Aerodynamic Preliminary Analysis System II, " Part II Users Manual, NASA CR-
165628, 1981.

[4] Mukhopadhyay, V.; Newsom, J. R.; and Abel, I.: "A Method for Obtaining Reduced-Order Control Laws for High-Order Systems Using Optimization Techniques," NASA TP 1876, 1981.

[5] Tiffany, S. H.; and Adams, W. M., Jr.: "Nonlinear Programming Extensions to Rational Function Approximation Methods for Unsteady Aerodynamic
Forces," NASA TP-2776, July 1988.

[6] Gilbert, M. G.; Heeg, J.; Pototzky, A. S.; Spain, C. V.; Soistmann, D. L.; Dunn, H. J.: "The Application of Active Controls Technology to a Generic Hypersonic Aircraft Configuration," NASA TM-101689, January 1990.

[7] Doyle, J. C.; and Stein, G.: "Multivariable Feedback Design: Concepts for a Classical / Modern Synthesis," IEEE Trans. Autom. Control AC-26,4-

[8] Brogan, W. L.: "Modern Control Theory," PrenticeHall Inc., 2nd edition, 1985.

[9] Federal Aviation Regulations, Part 25 "Airworthiness Standards: Transport Category 


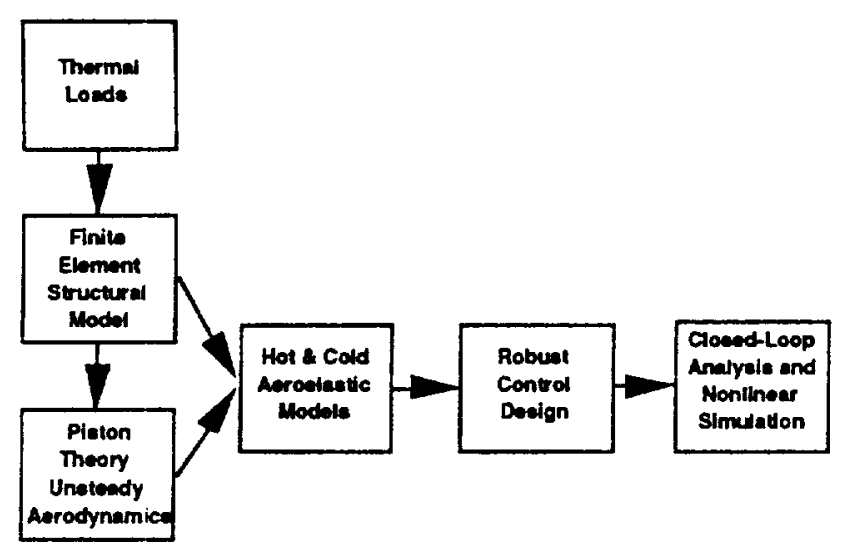

Figure 1. Hypersonic Analysis and Design Approach.

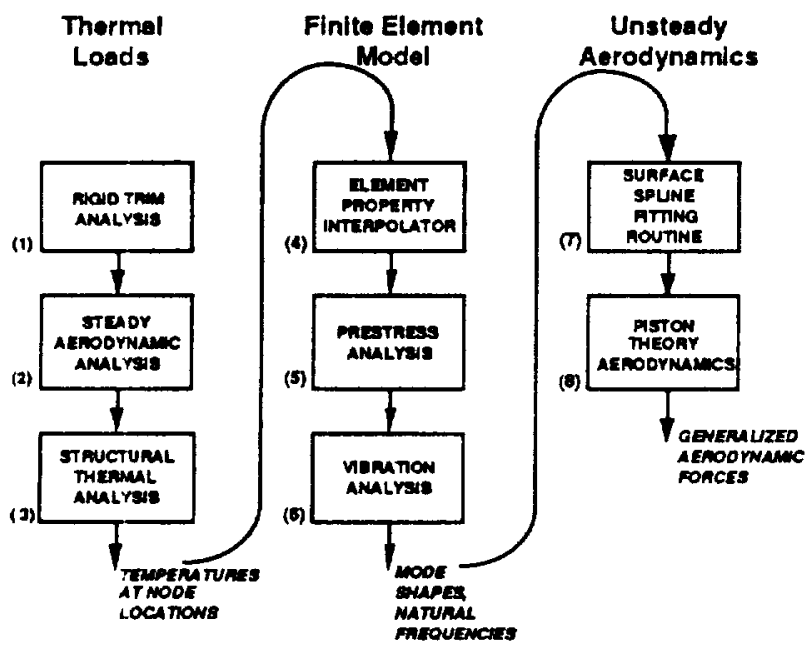

Figure 2. Modeling Flow Chart.

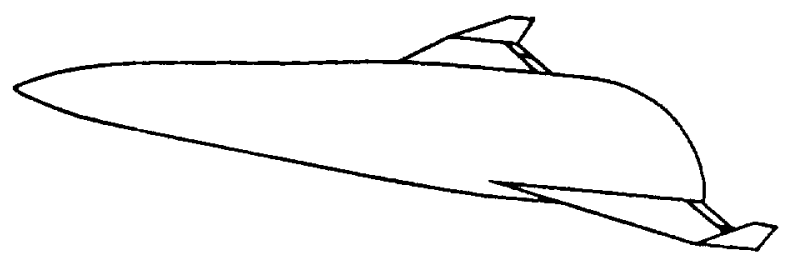

Figure 3. Generic Configuration.

\begin{tabular}{|l|c|}
\hline DESCRIPTION & \\
\hline Vehicle Length & $200 . \mathrm{ft}$ \\
\hline Wing Area & $1445 . \mathrm{ft}$ \\
\hline Span & $68.33 \mathrm{ft}$ \\
\hline Root Chord & $66.67 \mathrm{ft}$ \\
\hline Flap and Aileron Chord & $3.33 \mathrm{ft}$ \\
\hline Fin Height & $5.56 \mathrm{ft}$ \\
\hline
\end{tabular}

\begin{tabular}{|l|c|}
\hline Weight & $300,122 \mathrm{lb}$ \\
\hline$I_{x x}$ & $5.87 \times 10^{7} \mathrm{lb}-\mathrm{ft}^{2}$ \\
\hline$I_{y y}$ & $8.446 \times 10^{8} \mathrm{lb}-\mathrm{ft}^{2}$ \\
\hline$I_{z x}$ & $8.84 \times 10^{8} \mathrm{lb}-\mathrm{ft}^{2}$ \\
\hline
\end{tabular}

Table 1. Geometric and Inertial Description of Generic Configurations.

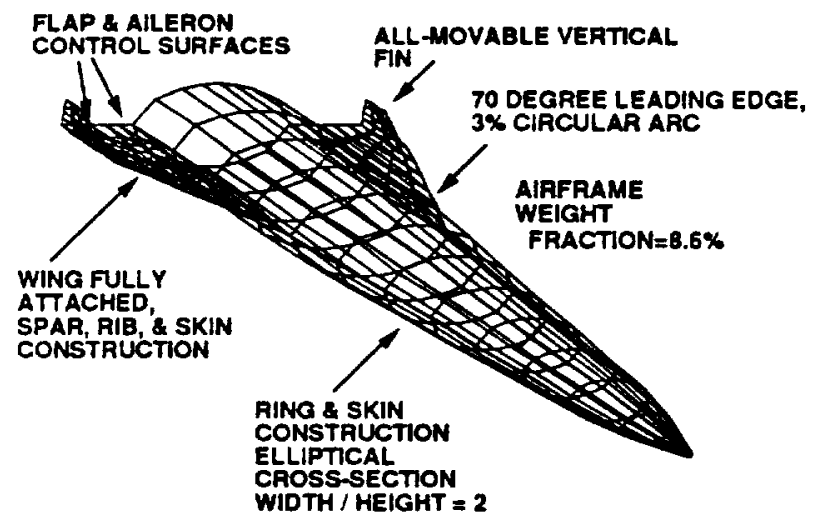

Figure 4. Finite Element Structural Model.
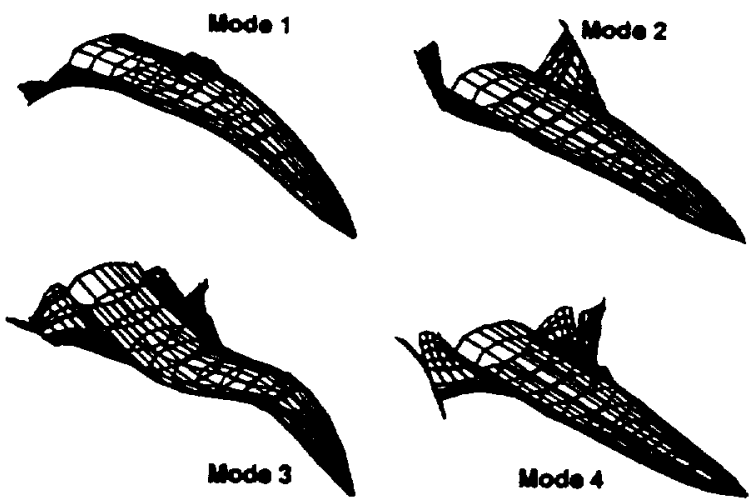

Figure 5. Vehicle Vibration Mode Shapes. 


\begin{tabular}{|c|c|c|c|c|}
\hline \multirow[t]{2}{*}{ MODE } & \multirow[t]{2}{*}{ DESCRIPTION } & \multicolumn{2}{|c|}{ FREOUENCY (HZ) } & \multirow{2}{*}{$\frac{\text { X AEDUCTION }}{\left.\text { ( } \frac{\text { COLPHOT }}{\text { COLD }}\right)}$} \\
\hline & & COLD & HOT & \\
\hline 1 & $\begin{array}{l}\text { fuseloge } \\
\text { bending }\end{array}$ & 3.01 & 2.43 & 10.3 \\
\hline 2 & wing & 4.02 & 3.48 & 13.4 \\
\hline 3 & $\begin{array}{l}\text { econd } \\
\text { huseulege } \\
\text { bendhng }\end{array}$ & 7.06 & 5.67 & 10.7 \\
\hline 4 & $\begin{array}{l}\text { wing } \\
\text { torion }\end{array}$ & 7.70 & 6.56 & 14.8 \\
\hline 5 & $\begin{array}{l}\text { All-movable } \\
\text { iln mode }\end{array}$ & 0.47 & 7.83 & 19.4 \\
\hline 6 & $\begin{array}{l}\text { hlghly coupled } \\
\text { mode }\end{array}$ & 10.26 & 8.84 & 19.3 \\
\hline
\end{tabular}

Table 2. Vibration Mode Descriptions and Natural Frequencies.

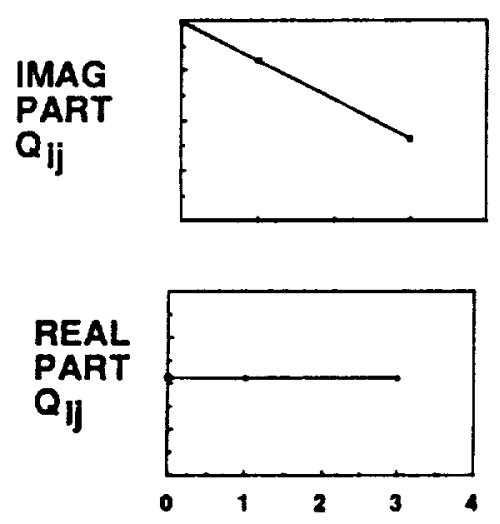

REDUCED FREQUENCY, $k(b \boldsymbol{w} / V)$

Figure 6. Lift Due to Pitch Displacement Genralized Aerodynamic Force.

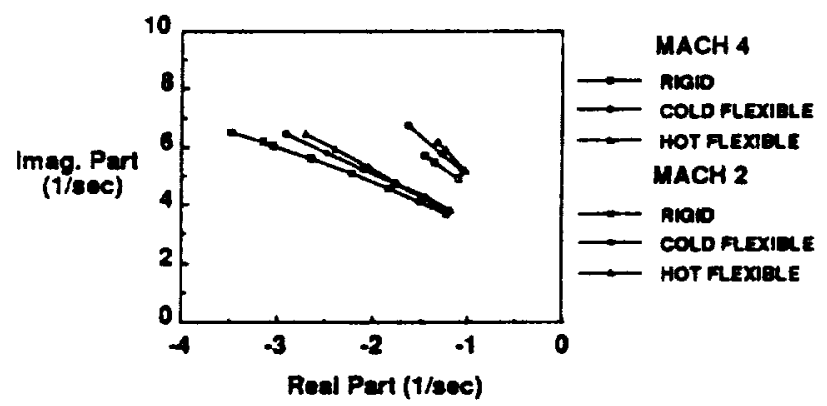

Figure 7. Effects of Mach Number, Heating, and Flexibility on the Short Period Mode.

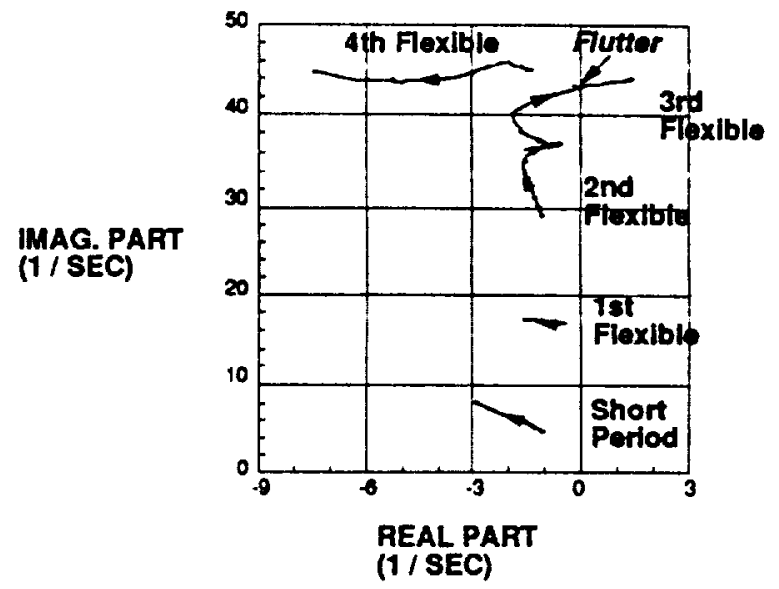

Figure 8. Altitude Root Locus for Mach 2 Heated Configuration.

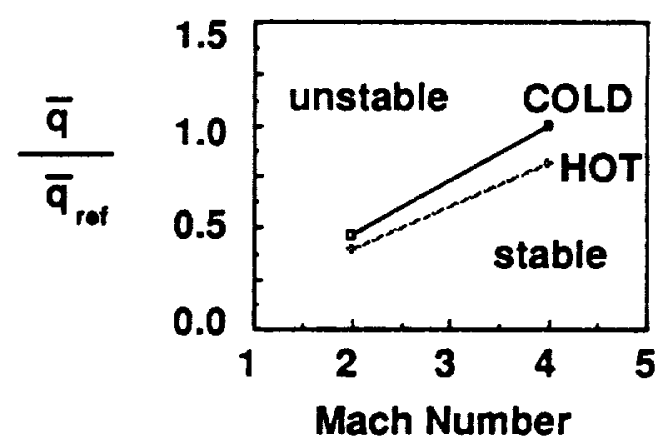

Figure 9. Flutter Boundaries.

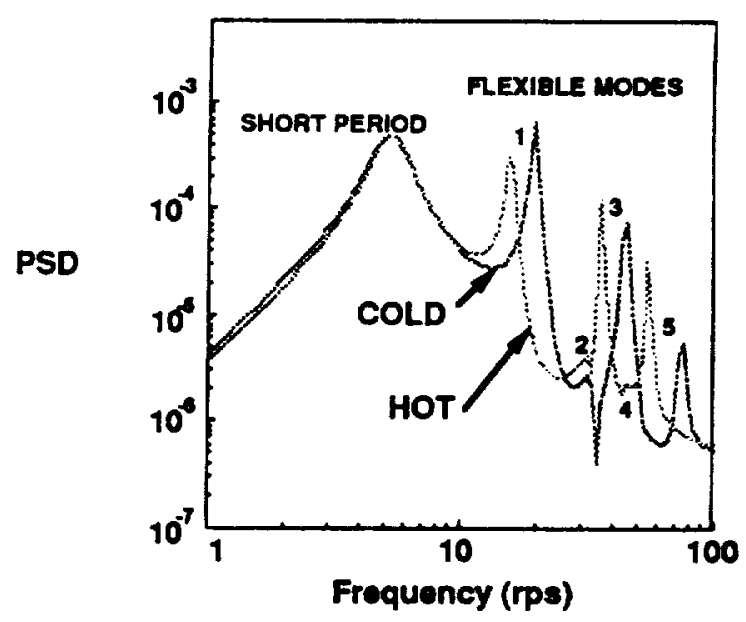

Figure 10. Open Loop Normal Acceleration Response at the Pilot Station Due to a $1 \mathrm{ft} / \mathrm{sec}$. Gust. 


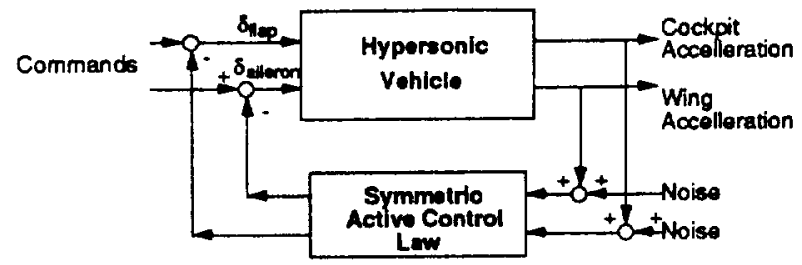

Figure 11. Schematic of Feedback Control System for FSS and RQAS.

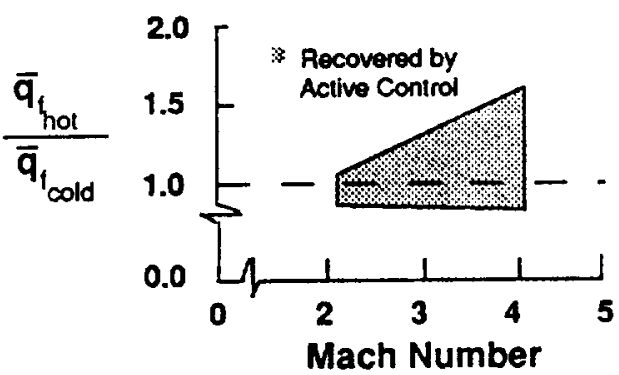

Figure 12. Flutter Suppression Results.

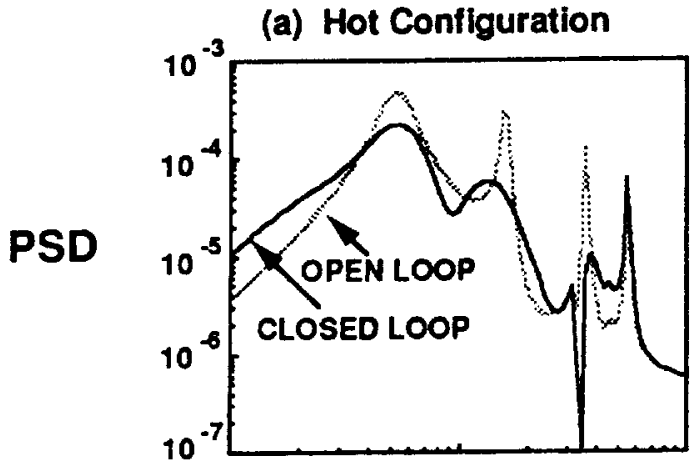

(b) Cold Configuration

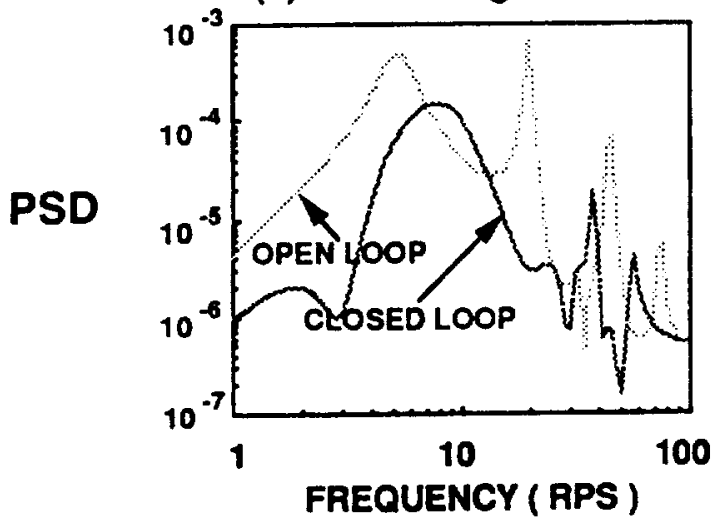

Figure 13. Power Spectral Densities: Normal Acceleration at the Pilot Station Due to a $1 \mathrm{ft} / \mathrm{sec}$. Gust. 


\begin{tabular}{|c|c|c|c|c|}
\hline 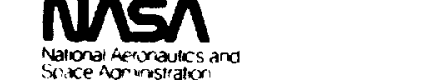 & \multicolumn{4}{|c|}{ Report Documentation Page } \\
\hline $\begin{array}{l}\text { 1. Report No. } \\
\text { NASA TM-102713 }\end{array}$ & \multicolumn{2}{|c|}{ 2. Government Accession No. } & \multicolumn{2}{|c|}{ 3. Recipient's Catalog No. } \\
\hline \multirow{2}{*}{\multicolumn{3}{|c|}{$\begin{array}{l}\text { 4. Title and Subtitle } \\
\text { Active Control of Aerothermoelastic Effects for a } \\
\text { Conceptual Hypersonic Aircraft }\end{array}$}} & \multicolumn{2}{|c|}{$\begin{array}{l}\text { 5. Report Date } \\
\text { August } 1990\end{array}$} \\
\hline & & & \multicolumn{2}{|c|}{ 6. Performing Organization Code } \\
\hline \multirow{2}{*}{$\begin{array}{l}\text { 7. Author(s) } \\
\text { Jennifer Heeg } \\
\text { Michael G. Gilbert } \\
\text { Anthony S. Pototzky }\end{array}$} & & & \multicolumn{2}{|c|}{ 8. Performing Organization Repont No. } \\
\hline & & & \multicolumn{2}{|c|}{$\begin{array}{l}\text { 10. Work Unit No. } \\
505-63-21-04\end{array}$} \\
\hline $\begin{array}{l}\text { NASA Langley Research } \\
\text { Hampton, VA 23665-52 }\end{array}$ & & & \multicolumn{2}{|c|}{ 11. Contract or Grant No. } \\
\hline \multirow{2}{*}{\multicolumn{3}{|c|}{$\begin{array}{l}\text { 12. Spansoring Agency Name and Address } \\
\text { National Aeronautics and Space Administration } \\
\text { Washington, DC 20546-0001 }\end{array}$}} & \multicolumn{2}{|c|}{$\begin{array}{l}\text { 13. Type of Report and Period Covered } \\
\text { Technical Memorandum }\end{array}$} \\
\hline & & & \multicolumn{2}{|c|}{ 14. Sponsoring Agency Code } \\
\hline \multirow{2}{*}{\multicolumn{5}{|c|}{$\begin{array}{l}\text { 15. Supptementary Nores } \\
\text { This paper is to be presented at the } 1990 \text { AIAA Guidance, Navigation, and Control Conference } \\
\text { Portland, Oregon, August 20-22, } 1990 \\
\text { Jennifer Heeg and Michael G. Gilbert: NASA Langley Research Center, Hampton, Virginia. } \\
\text { A. S. Pototzky: Lockheed Engineering and Sciences Company, Hampton, Virginia. }\end{array}$}} \\
\hline & & & & \\
\hline \multicolumn{5}{|c|}{$\begin{array}{l}\text { This paper describes the procedures for and results of aeroservothermoelastic studies. The objective } \\
\text { of these studies were to develop the necessary procedures for performing an aeroelastic analysis of ar } \\
\text { aerodynamically heated vehicle and to analyze a configuration in the classical "cold" state and in a "hot } \\
\text { state. Major tasks include the development of the structural and aerodynamic models, open loof } \\
\text { analyses, design of active control laws for improving dynamic responses and analyses of the closed } \\
\text { loop vehicles. The analyses performed focused on flutter speed calculations, short period eigenvalue } \\
\text { trends and statistical analyses of the vehicle response to controls and turbulence. Improving the ride } \\
\text { quality of the vehicle and raising the flutter boundary of the aerodynamically-heated vehicle up to that of } \\
\text { the cold vehicle were the objectives of the control law design investigations. }\end{array}$} \\
\hline \multicolumn{2}{|c|}{$\begin{array}{l}\text { 17. Key Words (Suggesiod by Author(s)) } \\
\text { Aeroservolasticity }\end{array}$} & \multicolumn{3}{|c|}{$\begin{array}{l}\text { 18. Distribution Stetement } \\
\text { Unclassified - Unlimited } \\
\text { Subject Category - } 08\end{array}$} \\
\hline $\begin{array}{l}\text { 19. Security Clossif. (of this report) } \\
\text { Unclassified }\end{array}$ & $\begin{array}{l}\text { 20. Security Clessif. lof } \\
\text { Unclassified }\end{array}$ & his pagel & $\begin{array}{l}\text { 21. No. of peges } \\
10\end{array}$ & $\begin{array}{l}\text { 22. Price } \\
\mathrm{AO} 02\end{array}$ \\
\hline
\end{tabular}

